\title{
CULTURAL CHANGES IMPACT IN KOSOVAR STILES OF LEADERSHIP
}

\author{
Thëllëza Latifi Sadrija \\ Phd (c), Univeristy "Haxhi Zeka" \\ fllanzalatifi@hotmail.com
}

DOI:10.5901/mjss.2014.v5n22p287

\begin{abstract}
The use of the word culture in organizational analysis includes the effects of interactions between environmental organizations and the culture of the country where they are located. In Kosovo businesses styles of leadership differ from one another depending on the environment and organizational culture. Cultural differences play important roles in the organization, particularly in motivating subordinates and increasing the performance. In Kosovo businesses the impact of cultural change has not affected particularly good in terms of motivation and in adapting new cultures in our country especially since the after war period until now. Good business relationship have been developed through cultural groups and geographic boundaries, Kosovo is a in transition country with an unstable economy has not yet developed organizational culture due to the lack of various mechanisms as training, adoption and acceptance of new cultures. Is important to note that the adoption and creation of a new culture in our country depending will increase employees' performance that are influenced by democrat leadership style. The aim: Given the fact that the culture study is especially important today in terms of globalization and in Albanian culture there are few researches on cultural values and their influence in terms of management and for this reason is important to be focused on enhancing the sensitization to acceptance new cultures and adapt them in Kosovar companies. Performance evaluation aims, performance evaluation data are important information in order to judge validity of selection methods, to evaluate if such methods ensure a good selection of employee for organization. Performance evaluation can lead towards identification e needs of employees for further improvement. Performance evaluation ensures information for employees regarding their performances, information which will serve to employees as a foundation for improvement. Performance evaluation is tightly linked with motivation of employees. Coordination of knowledge and the talent of our consultants followed with experience is the most applied from human resources in the region, it allows you to implement Oracle HRMS within your organization rapidly.
\end{abstract}

Key words: Leadership, Organizational culture, business ethics, performance

\section{Introduction}

Based to the fact that leaders finish their duty in different styles, autocratic, democratic, participating laisseze faire (liberal) and often the leadership style dependsfrom the situation including organizationalcultural changes and which style do leaders use based to the culture and business label in Kosovo.

In Kosovar businesses there is a direct link between ethical leadership and moral organizational culture based to the researches main focus stands at the way of thinking that is after many changes including foreign by generations, in Kosovo dominates more aristocratic style, the period after the war time followed many changes including foreign stake holders that dominate also the transforming style of leadership, this approach of transforming leadershipstrong emphasizes pays to the paradigm of the level of the leadership lining on the charisma and personal sensitiveness of the leader. According to this approach the leader changes as all other people do, so the emotions, value, ethics, standard, are included in the group of motives of proponents so that the leader becomes part of their group in one transforming process it means the exchange is being done between the charismatic and visionary leadership.

The important matter is the combination of these two styles that in continuation of the leading of Kosovar businesses are growing the performance creating the new cultural era and ethical code applicable in all leading points

\section{Organizational Culture and Kosovar Leadership}

Organizational culture as a whole represents the values, norms, standards of behavior and common expectations, which control how individuals or groups in an organization. ???? 
Managers in the organization through values and norms control the results. Values are the trust and idea for the type of aims that the members of one society should follow as well as for the behavior that people should apply to reach their aims. While norms are written rules or instructions to fulfill for reaching goals. Except values and norms is important also organizational socialization, which is a process by which new employees learn the values and norms of the organization and to gain knowledge for the necessary organizational behavior for reaching the effective results.

The organizational culture and leadership interact with one another, the leaders create and reinforce norms and behavior within the culture...An organizational culture affects its leadership as the leadership affects the culture. (Bass B.M., 1998:63) So "...to improve the organization, the culture should be improved, and to improve the culture, personal effectiveness and leadership must be improved."(Terrell\&Nelson, 1998:1).

Organizational culture in Kosova conditioned by the leadership more transactional which work within their organizational culture following the existing rules, procedures and norms1, methods which do not bring effective results because of the not adapting culture which is essential for the success of the leader and organization. The Kosovar leadership should focus more at the transforming one which change their culture first understanding it and then reconstructing the culture of the organization with a new vision and reviewing of the common assumptions of values and norms Bass (1985). According to the transforming leadership that includes some assumptions as:

Articulate a vision and sense of purpose to their followers, b) serve as role models, teachers and coaches, $c$ ) work for the socialization of new members within a epitome of an organizational culture transformation, d) challenges are the opportunities and threats etc ..., methods and models of this type are effective networking leadership and cooperation with other countries nationwide because we are dealing with adaptive culture and virtues of a creative personality, .

\section{Cultural changes in Kosovar enterprises based to the norms of behavior in group}

Studies and different articles considered leadership main and integral part of social and cultural structures of the organization. Enterprising leadership as important part of the organization should reflect and present best directing qualities in achieving success through communication with people, influencing in the manner and its actions, encouraging in directing and fulfilling of the duties in group. All together helps in supporting of cultural changes of the organization and further development of the leadership. Implementation and appropriation of these qualities enables a leader to prepare, with a clear vision for the present and future.2

The same fact of the group and group behavior affect growth performance and realism of organizational objectives, involvement enables the individual to achieve the objectives set, to decrease the barriers, anxiety, feelings of helplessness, helps individuals to check opinions for work environment, the most important for career advancement.

The use of mechanisms to avoid group problems which influence in organizational performance of the culture and increasing the values at work it is more than necessary to restructure the processes of functioning in group, with better focus on heterogenic groups where the decision making is high quality, are more efficient in complex duties, not routine and which would affect in cultural changes where these changes would bring effectiveness and would create networking with foreign countries.

Behavior at work presents:

$P R^{\star} A^{\star} M=$ Behavior at work;

PR- Perceptions of the role;

\section{A-Abilities and Mastering.}

Based on researches done in Kosovo organizations we have a combination of group behavior whether they want leadership style and personality of its own, but the largest percentage of focus group style homogeny groups, have less conflicts, are less effective in complex tasks and non-routine.

\section{Purposes of evaluation of the performance in leading enterprises}

${ }^{1}$ Gjurkaj. E "National Culture in organizational culture", Tiranë.page 50,51, 2013

${ }^{2}$ www.mod.gov.al/publishing/html/army/2007/.../page.htm 
To identify the level of the performance conditioned by the ethics and organizational culture.

To equip managers with a tool for identifying the strong and weak points of the performance for employers.

To provide a format that gives possibility to managers to recommend a specific program projected to help an employee to improve the performance.

To offer possibilities for the employers to get rewards for the given contribution for aims of the organization.

To have information regarding further planning.

The goals of evaluations aim first to see work implementation of the employees and the successes that they achieved during the implementation of work compared with standards of the performance within the certain period.

The new methods of the evaluation with emphasize on treatment and plans for development and growth of the employees. Treatment is aimed at improving the assessment of work behavior conditioned by organizational ethics.1.

\subsection{Reward of evaluated performance}

The creating of the reward programs requests from all organizations to set specific goals as: retention of workers, labor compensation and budget support. The compensation should reward employees for the work being done serving as motivation for the performance of the employees on the future. The most common purposes of remuneration policy include:

To reward employees for past performance

To remain competitive in the labor market

To ensure equality of pay between employees

To motivate next performances

To attract new employees

To reduce unnecessary returns.

The main tool of reward of the achieved performance is salary for performance and that depends also from the politics and the budget of the enterprise, this we will show on the following drawing.

The process of the reward for performance 2

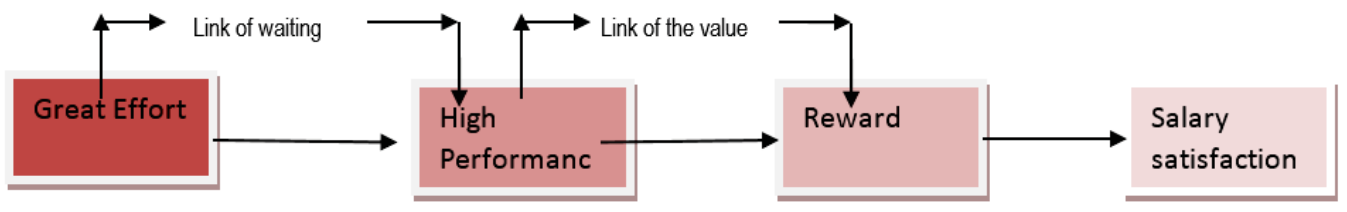

\section{LEVEL OF ANALYSING OF TREATMENT}

Registered enterprises in Kosovo based to the number of the employees -20103

\begin{tabular}{|l|l|l|l|}
\hline Clasification by size & $\begin{array}{l}\text { Number of } \\
\text { employees }\end{array}$ & Number of enterprises & Percentage in total \\
\hline Micro & $1-9$ & 102,070 & 98.37 \\
\hline Small & $10-49$ & 1,406 & 1.35 \\
\hline Medium & $50-249$ & 221 & 0.22 \\
\hline Big & More then 250 & 58 & 0.06 \\
\hline
\end{tabular}

\footnotetext{
1 Sherman, Bohlaner, Snell, "Human Resources Management", 1997,page. 176

2Sherman, Bohlander\& Snell "Human Resources Management", 1997, page.201

${ }^{3}$ Strategy of development of NVMin Kosova 2012-2020, fq.17
} 


\begin{tabular}{|l|l|l|l|}
\hline Total & 103,755 & 100.00 \\
\hline
\end{tabular}

Source ARBK

From total 103.755 enterprises: 102.070 (or 98.37\%) are micro enterprises; 1.406 (1.35\%) are small; 221 (0.22\%) are medium and only $58(0.06 \%)$ are classified as big.Prevalence of micro-enterprises has implications for the SME Strategy.

The analysis of labor will focus in macro enterprises and the importance of the labor stands at the ethics and culture of the leadership in Kosovar enterprises where is necessary to have a bigger number of the employees in order to be measurable results achieved by the Kosovo leadership influence.

Crucial variables of the work are: ethics and organizational culture, based on these variables we will present a comprehensive survey that confirms the importance of cultural change and adaptation of cultures needed for a high performance based on transactional leadership.

Presenting of the results:

Number of managers in all enterprises in Kosova is 58and the sum of these will draw results presented in table in \%

\begin{tabular}{|c|c|c|}
\hline Is ethical code recognized at your company? & No & Percentage \\
\hline Yes & 45 & $77.5 \%$ \\
\hline No & 13 & $22.4 \%$ \\
\hline Maybe & 0 & $0 \%$ \\
\hline Is it being applicable the ethical code? & No & Percentage \\
\hline More & 40 & $69 \%$ \\
\hline Less & 18 & $31 \%$ \\
\hline None & 7 & $43 \%$ \\
\hline Does the ethic of work have influence in performance of the enterprise? & No & Percentage \\
\hline More & 50 & $86.2 \%$ \\
\hline Less & 5 & $8.62 \%$ \\
\hline None & 3 & $5.17 \%$ \\
\hline In your enterprise is it being used transforming or transactional model of leadership? & No & Percentage \\
\hline Transforming & 25 & $43.1 \%$ \\
\hline Transactional & 32 & $55.17 \%$ \\
\hline None & 1 & $1.72 \%$ \\
\hline How much impact has the leader on enhancing group? & No & Percentage \\
\hline More & 38 & $65.51 \%$ \\
\hline Less & 18 & $31 \%$ \\
\hline None & 2 & $3.44 \%$ \\
\hline What problems / obstacles foresee the leader in your company? & No & Percentage \\
\hline Personal & 4 & $6.89 \%$ \\
\hline Neighborhood & 18 & $31 \%$ \\
\hline External & 36 & $62 \%$ \\
\hline
\end{tabular}




\begin{tabular}{|lcc|}
\hline What characterizes the culture of the organization? & No & Percentage \\
\hline National culture & 33 & $67 \%$ \\
\hline Cooperating leadership & 10 & $40 \%$ \\
\hline $\begin{array}{l}\text { Ethics } \\
\text { Which culture is being developed in mentioned enterprises regarding effective decision } \\
\text { making? }\end{array}$ & 7 & $43 \%$ \\
\hline Adaptive culture & 20 & Percentage \\
\hline Not adaptive culture & 30 & $34.48 \%$ \\
\hline None & 8 & $13.72 \%$ \\
\hline What kind of impact has cultural changes in your enterprise? & No & Percentag \\
\hline Effective influence & & e \\
\hline Not effective influence & 30 & $51.72 \%$ \\
\hline None & 22 & $37.93 \%$ \\
\hline
\end{tabular}

\section{Recommendations:}

Based to these extensive questions in macro enterprises in Kosovo we come to the conclusion that:

Kosovar leadership should focus more in developing of the new culture as for example to use mechanisms which help in cooperation and exchange between Kosovar personnel and the international ones.

Enterprises to be adaptable to new cultures, to have more experiences about ethics and its implementation.

To request assistance from experts from abroad to this matter, since that the knowledge and experiences of developed countries can help build a better system of organizational culture which results process will create opportunities for better results in this enterprise.

Creating a positive and reliable atmosphere for employees and inform employees of the importance of performance evaluation process, in enhancing the quality of services, the fulfilling of the objectives of the enterprise.

Informing staff aboutconducted performance oriented more in the formal way and the informing about performance, to be provided in group meetings and since that the application of this form can be affected as a motivator in achieving high performance of work of the personel.

\section{References:}

Gjurkaj .E . "National Culture in Organizational Culture" Tirana, 2013

Sherman, Bohlaner, Snell, "Human Resources Management", 1997

Sherman, Bohlander\& Snell "HumanRresources Management", 1997

Development Strategy of NVM in Kosovo 2012-2020

www.mod.gov.al/publishing/html/army/2007/... 